\title{
DOSES REDUZIDAS DE HERBICIDAS HORMONAIS NO CONTROLE DE Sidastrum micranthum
}

\author{
Leandro Estevão dos SANTOS $^{1}$ \\ Oscar Mitsuo YAMASHITA ${ }^{2}$ \\ Marco Antônio Camillo de CARVALHO ${ }^{2}$ \\ Ricardo Adriano FELITO ${ }^{3}$ \\ Adriano Maltezo da ROCHA ${ }^{3}$ \\ Aureane Cristina Teixeira FERREIRA ${ }^{3}$ \\ Teli Cristiane Briekowiec KREMER ${ }^{3}$ \\ Paulo Cesar Laurindo SILVA ${ }^{3}$
}

${ }^{1}$ Engenheiro Agrônomo. Universidade do Estado de Mato Grosso. egregyo @ hotmail.com;

${ }^{2}$ Prof. Programa de Pós-graduação em Biodiversidade e Agroecossistemas Amazônicos da Universidade do Estado de Mato Grosso, yama@unemat.br; marcocarvalho@unemat.br

${ }^{3}$ Mestrando do Programa de Pós-graduação em Biodiversidade e Agroecossistemas Amazônicos da Universidade do Estado de Mato Grosso, Campus de Alta Floresta, ricardofelito@hotmail.com; aurianeferreira@hotmail.com; adrianomaltezo@gmail.com

Recebido em: 18/03/2016 - Aprovado em: 27/06/2016 - Disponibilizado em: 30/07/2016

RESUMO: O sucesso da produção pecuária brasileira está estreitamente relacionado com a manutenção adequada das pastagens. Pastagens degradadas pela presença de plantas daninhas constituem se, atualmente, em um dos maiores problemas desse setor, reduzindo a produtividade e a qualidade da forrageira. Objetivou-se, neste trabalho verificar a ação de subdoses de herbicidas no controle da planta daninha "malva" em área de pastagem. O delineamento experimental foi em blocos casualizados, com 10 tratamentos distribuídos em esquema fatorial ( 2 x 5), sendo 2 herbicidas aplicados em 5 doses: 2,4-D e a formulação 2,4-D+picloram, em: $0 ; 3 ; 6 ; 12,5$ e $25 \%$ da dose recomendada para controle de plantas daninhas em culturas perenes (4,0 L ha-1). Foram realizadas avaliações de controle na malva e determinação da altura das plantas aos 7; 14; 21 e 28 dias após a aplicação, além da fitointoxicação no capim braquiária nas mesmas datas de avaliação. Não houve sintoma de fitointoxicação na forrageira. Controle igual ou superior a $90 \%$ de malva foi verificado a partir das doses de $12,5 \%$ da dose recomendada de 2,4-D+picloram e 25\% de 2,4-D. Os herbicidas foram eficientes no controle da espécie, mesmo em doses inferiores ao recomendado para espécies de difícil controle.

Palavras-chave: Planta Daninha. Malva. 2,4-D. Picloram. Pastagem.

\section{REDUCED RATES OF HORMONAL HERBICIDES TO CONTROL OF Sidastrum micranthum}

\begin{abstract}
The success of Brazilian livestock production is closely related to the proper maintenance of pastures. Pastures degraded by the presence of weeds are up currently, one of the biggest problems of this sector, reducing the yield and quality of forage. The aim of this study was to investigate the action of sublethal herbicide to control of Sidastrum micranthum in pasture. The experimental design was a randomized block design with three replications and 10 treatments arranged in a factorial $(2 \times 5)$, and 2 herbicides applied in 5 doses, 2,4-D and formulation of 2,4-D+picloram at doses from: $0,3,6,12.5$ and $25 \%$ of the recommended dose for weed control in perennial crops $(4,0 \mathrm{~L}$ ha-1). We evaluated control in S. micranthum and determination of plant height at 7, 14, 21 and 28 DAA (days after application) and phytointoxication in
\end{abstract}


Brachiaria grass in the same evaluations. There was no symptom of phytointoxication forage. Control less than $90 \%$ mallow was found from dose $12.5 \%$ of the recommended dose of 2,4-D+picloram and $25 \%$ of 2,4-D. The herbicides used were efficient in controlling weed species at lower doses than recommended for species difficult to control.

Keywords: Weed. Malva. 2,4-D. Picloram. Pasture.

\section{INTRODUÇÃO}

A pecuária bovina no Brasil sofre na atualidade as consequiências da exploração extrativista, historicamente adotada pelos produtores. Esse fato determinou um processo avançado de degradação de grandes áreas de pastagem, constituindo um dos principais entraves ao desenvolvimento dessa atividade em sua plenitude, com reflexos negativos em toda a cadeia produtiva da carne (PAULINO et al., 2012).

Admite-se que, atualmente, a degradação dos pastos seja o maior problema da pecuária bovina no país (LADEIRA NETO et al., 2006). Estima-se que $80 \%$ das pastagens implantadas na região dos Cerrados apresentam algum nível de degradação (GIORDANO, 2012).

A elevada ocorrência de plantas invasoras em pastagens degradadas ou em processo de degradação representa um agravante ao processo de perda de produtividade dos pastos (DUTRA et al., 2002; INOUE et al., 2012). Os prejuízos causados às pastagens pelas plantas invasoras, especialmente aquelas de folhas largas, podem ocorrer desde o período da formação, quando as condições de implantação das forrageiras não são adequadas, resultando em atraso na ocupação da pastagem pelos animais (POTT et al., 2006). Posteriormente, a falta de manutenção da fertilidade do solo e o manejo inadequado das pastagens, favorecem a disseminação das plantas daninhas e reduzem a produtividade ao longo dos anos de utilização (COSTA et al., 2006).

O custo de controle químico dessas plantas é alto, visto que a maioria dos pecuaristas, para o controle de plantas invasoras de pastagens, utilizam doses superiores às necessárias para o controle de diversas plantas invasoras (VICTÓRIA FILHO, 1985; SILVA et al., 2007; CASTRO JUNIOR et al., 2008).

A malva (Sidastrum micranthum) é uma planta invasora de pastagens, que ocorre com frequência em diversos países do mundo como Cuba, Costa Rica, Venezuela, Guiana, Índia e Brasil (LORENZI, 2000; BOVINI et al., 2001; SHIMPALE et al., 2009). Na região central do Brasil, esta planta daninha tem provocado redução na capacidade de pastejo dada sua competição por água, luz, nutrientes e principalmente espaço físico nas áreas de pecuária (POTT et al., 2006).

Como esta e outras espécies invasoras de pastagens tornam-se predominantes, prejudicando o desenvolvimento da forrageira, normalmente recorre-se exclusivamente ao controle químico, utilizando-se para isso, principalmente herbicidas do grupo químico dos mimetizadores de auxinas (LADEIRA NETO et al., 2006). Entretanto, diferentemente de outras espécies, como Vernonia ferruginea, 
Senna obtusifolia e Vismia guianensis, não há relatos quanto a dificuldade no controle químico desta espécie (ALBERGUINI e YAMASHITA, 2010; DUTRA et al., 2002).

Assim, a dosagem de determinado herbicida pode estar sendo superestimada, ou seja, o uso de quantidades menores pode promover controle eficaz dessa invasora, quando esta ocorre em infestações uniformes em determinados talhões das áreas de pastagem.

Assim, o manejo químico, integrado a outras práticas, pode ser efetivo e menos impactante ao ambiente, dependendo das espécies presentes na área. Em estudos de métodos integrados de controle de plantas daninhas em Brachiaria brizantha no Pará (roçada manual, roçada manual + queima e gradagem, associados ou não ao herbicida 2,4D nas concentrações de 1, 2 e 3\%), verificou-se (DUTRA et al., 2002) que com a integração de métodos, ou seja, o uso de métodos físicos e o método químico, o controle das espécies infestantes foi efetivo. Entretanto, sem a associação com o controle químico, os métodos físicos foram ineficazes para o controle das plantas daninhas. $\mathrm{O}$ estudo mostrou que qualquer dos métodos físicos avaliados, associados a uma aplicação de 2,4-D a uma concentração média de $2,2 \%$, proporcionam a máxima resposta da Brachiaria brizantha e supressão das infestantes.

Foi realizada a presente pesquisa com o objetivo de verificar a ação de doses reduzidas de herbicidas mimetizadores de auxinas no controle de malva em área de pastagem.

\section{MATERIAL E MÉTODOS}

O trabalho foi conduzido na Fazenda Boa Vista, localizada no município de Alta Floresta - MT a 0956'34' de latitude sul e 55 $55^{\prime} 71^{\prime \prime}$ de longitude oeste, numa altitude de $384 \mathrm{~m}$. A precipitação média anual é de 2.750 mm e a temperatura média anual é de $26{ }^{\circ} \mathrm{C}$. O solo do local é da classe Latossolo VermelhoAmarelo distrófico típico argiloso (EMBRAPA, 2013).

A pesquisa foi conduzida no período compreendido entre janeiro e março de 2004, em área de pastagem formada há 15 anos com Brachiaria brizantha, onde a infestação de malva ( $S$. micranthum) era homogênea e uniforme, apresentando em média 8 plantas por metro quadrado.

O delineamento experimental adotado para o ensaio de campo, foi em blocos casualizados no esquema fatorial 2 × 5 (dois tipos de herbicidas e cinco doses), com 3 repetições, perfazendo um total de 30 parcelas. Os herbicidas utilizados foram 2,4-D $\left(\mathrm{Aminol}^{\circledR}\right)$ (670 $\mathrm{g} \mathrm{L}^{-1}$ e.a.) e 2,4-D em mistura comercial com picloram $\left(\right.$ Tordon $\left.^{\circledR}\right)\left(240\right.$ g L $^{-1}$ e.a. +64 g $\mathrm{L}^{-1}$ e.a.), sendo que para cada herbicida foram usadas as seguintes doses: 0,$3 ; 6 ; 12,5$ e $25 \%$ da dose recomendada para controle de daninhas em pastagem, ou seja, 4,0 $\mathrm{L} \mathrm{ha}^{-1}$ (RODRIGUES e ALMEIDA, 2005).

Cada parcela apresentava área total de 6 $\mathrm{m}^{2}$, com 3 metros de comprimento, por 2 metros de largura, com população média de 8 plantas por metro quadrado. 
Para a aplicação, foi utilizado um pulverizador costal manual, portando ponta de jato plano XR110.01, trabalhando á pressão constante de $280 \mathrm{KPa}$, mantida por $\mathrm{CO}_{2}$, com gasto de calda de $300 \mathrm{~L} \mathrm{ha}^{-1}$. A aplicação foi realizada no período da manhã, objetivando-se temperatura ambiente mais amena e umidade relativa do ar mais elevada, observando-se também recomendações de ausência de ventos e de orvalho sobre as folhas da malva.

Os tratamentos foram avaliados aos 7 , 14, 21 e 28 dias após a aplicação (DAA), sempre no mesmo horário, visando evitar distorções nas avaliações por influência do ambiente (reflexo da luz, sombreamento), sendo coletadas as seguintes variáveis:

Controle da malva - foram realizadas avaliações visuais de controle por meio de notas, com escala de 0 a 10 , onde 0 era a ausência de controle e 10 caracterizava a morte da planta.

Altura de plantas - a altura das plantas foi tomada medindo-se aleatoriamente 5 plantas dentro da área útil de cada parcela, da região do colo da planta até a gema terminal da haste principal.

Fitointoxicação da B. brizantha - nos mesmos dias de avaliação do controle da malva, foi realizada a avaliação de fitointoxicação da forrageira, atribuindo-se notas que variaram de 0 a 10 , sendo 0 a ausência de sintomas de fitointoxicação e 10 a morte da gramínea.

Os dados coletados foram submetidos à análise de variância, comparando-se as médias das variáveis quantitativas pelo teste de Scott \&
Knott. Foi utilizado o nível de $5 \%$ de probabilidade. Havendo significância, realizouse análise de regressão que permitisse melhor caracterizar o efeito avaliado.

\section{RESULTADOS E DISCUSSÃO}

Quanto ao controle da malva, este foi influenciado pela dose $(\mathrm{p}<0,05)$ aos 7, 14, 21 e 28 dias após aplicação (DAA), pelo herbicida $(\mathrm{p}<0,05)$ aos 7 dias e pela interação entre esses dois fatores aos 7 e 28 dias após aplicação (p < 0,05). Para a variável altura de planta, observou-se apenas a influência da dose nas duas últimas avaliações, ou seja, aos 21 e 28 DAA $(\mathrm{p}<0,05)$ (Tabela 1). Não houve qualquer sintoma de fitointoxicação na forrageira, demonstrando que os herbicidas usados são totalmente seletivos para $B$. brizantha, motivo pelo qual não foi realizada análise estatística desta variável.

Já na primeira avaliação realizada aos 7

DAA, era observada nitidamente a caracterização de intoxicação nas plantas de malva, que apresentaram epinastia visível e crescente à medida que as doses foram aumentadas (Figura 1-A). Esses sintomas são característicos de herbicidas do grupo químico dos mimetizadores de auxina, sendo relatados em diversos trabalhos (VICTÓRIA FILHO, 1985; FAGLIARI et al., 2004; CONSTANTIN et al., 2007). Na avaliação aos 7 DAA, observou-se que a mistura de picloram no herbicida promoveu maior eficiência de controle da malva, em comparação ao 2,4-D usado isoladamente. 
Tabela 1. Quadrado médio das variáveis CONTROLE e ALTURA DE PLANTAS de malva (Sidastrum micranthum) com diferentes herbicidas, em doses crescentes, avaliado aos 7, 14, 21 e 28 dias após a aplicação dos herbicidas.

\begin{tabular}{lcccc}
\hline \multicolumn{1}{c}{ Fonte de } & \multicolumn{4}{c}{ Avaliação de controle (dias) } \\
\cline { 2 - 5 } \multicolumn{1}{c}{ variãa } & 7 & 14 & 21 & 28 \\
\hline Herbicida (H) & $10,80^{*}$ & $3,01 \mathrm{~ns}$ & $1,63 \mathrm{~ns}$ & $0,83 \mathrm{~ns}$ \\
Dose (D) & $51,72^{*}$ & $78,84^{*}$ & $90,03^{*}$ & $102,88^{*}$ \\
H*D & $3,71^{*}$ & $1,59 \mathrm{~ns}$ & $1,99 \mathrm{~ns}$ & $3,58^{*}$ \\
Bloco & 1,43 & 0,06 & 0,53 & 0,01 \\
Erro & 0,36 & 0,58 & 0,76 & 0,45 \\
\hline C.V. (\%) & 16,05 & 18,16 & 18,36 & 14,12 \\
\hline & & Altura de plantas (dias) \\
\cline { 2 - 5 } & 7 & 14 & 21 & 28 \\
\hline Herbicida (H) & $22,53 \mathrm{~ns}$ & $58,80 \mathrm{~ns}$ & $0,30 \mathrm{~ns}$ & $16,13 \mathrm{~ns}$ \\
Dose (D) & $71,37 \mathrm{~ns}$ & $176,46 \mathrm{~ns}$ & $1819,88^{*}$ & $2439,05^{*}$ \\
H*D & $52,37 \mathrm{~ns}$ & $96,30 \mathrm{~ns}$ & $62,88 \mathrm{~ns}$ & $36,38 \mathrm{~ns}$ \\
Bloco & 376,90 & 79,43 & 85,83 & 147,23 \\
Erro & 86,75 & 126,40 & 221,80 & 211,97 \\
\hline C.V. (\%) & 5,20 & 6,12 & 8,02 & 7,63
\end{tabular}

$\mathrm{ns}=$ não significativo pelo teste $\mathrm{F} . *$ = significativo a $5 \%$ de probabilidade pelo teste $\mathrm{F}$

Os tratamentos com 2,4-D + picloram apresentaram efeitos danosos a partir da menor dose (3\%), com controle crescente das plantas daninhas. Enquanto que o herbicida 2,4-D isolado, não promoveu diferença significativa entre as doses de 6 e 12\%. Na interação entre herbicida e dose, houve semelhança na resposta ao controle das plantas nas menores doses (3 e 6\%). A partir daí, os herbicidas se diferiram e o tratamento com herbicida 2,4-D isolado, promoveu maior controle nas plantas, chegando a apresentar o dobro das notas na dose maior, enquanto o herbicida 2,4-D+picloram teve evolução mais lenta e moderada. Maiores notas de controle da planta daninha foram atribuídas quando foram aplicadas as maiores doses de ambos os herbicidas, havendo nítida superioridade quando foi usado a mistura de 2,4-D com picloram.
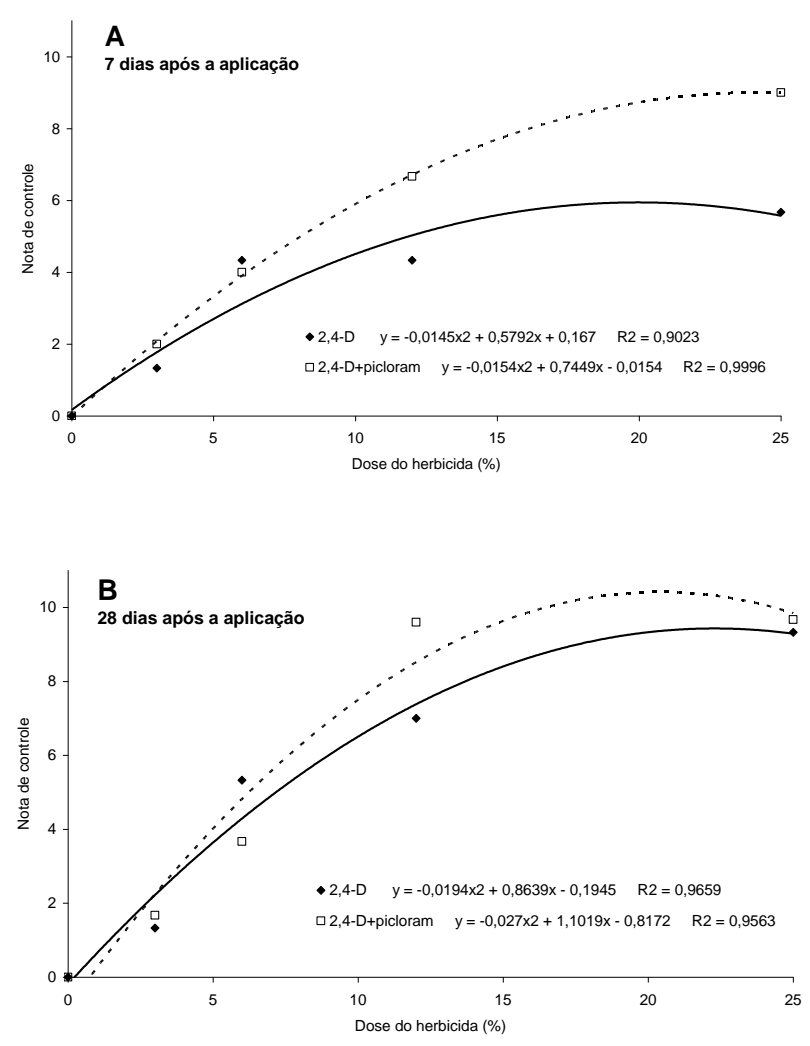

Figura 1. Controle de malva (Sidastrum micranthum) em função da aplicação de doses crecentes dos herbicidas 2,4-D e 2,4-D+picloram, aos 7(A) e 28(B) dias após a aplicação.

A presença do picloram potencializa o efeito do herbicida, provocando o controle efetivo de diversas plantas daninhas lenhosas. (PASSINI e KRANZ, 1997) observaram controle satisfatório de Tecoma stans após a aplicação de 2,4-D+picloram a 4\%, apesar de ser comparativamente mais lento que o tebuthiuron. 
Aos 14 DAA, controle foi mais efetivo, apresentando maiores notas de maneira crescente e progressiva (Figura 2) para ambos os herbicidas. Os sintomas de fitotoxicidade no herbicida 2,4-D foram semelhantes aos observados quando se usou o 2,4-D+picloram. Para a maior dose, os herbicidas não se diferiram entre si. Verificou-se que as notas atribuídas às doses do 2,4-D+picloram apresentaram acentuada evolução, nitidamente observáveis a partir da dose de 12,5\%, que provocou fitotoxicidade duas vezes maior que a dose inferior (6\%). Já o herbicida 2,4-D manteve uma evolução de fitotoxicidade semelhante à avaliação realizada aos 7 DAA, exceto na maior dose, que evoluiu, nesse intervalo de tempo.

$\mathrm{Na} \quad 3^{\mathrm{a}}$ avaliação (21 DAA), para o herbicida 2,4-D, não se observou diferença entre as menores doses ( 3 e $6 \%$ ), tampouco entre as maiores doses (12,5 e 25\%). Ambos os herbicidas, provocaram efeito fitotóxico praticamente semelhante. Para o 2,4D+picloram, a menor dose (3\%) não se diferiu da testemunha, mas para $6 \%$, observou-se um acréscimo nas notas de controle quatro vezes maiores que a dose menor.

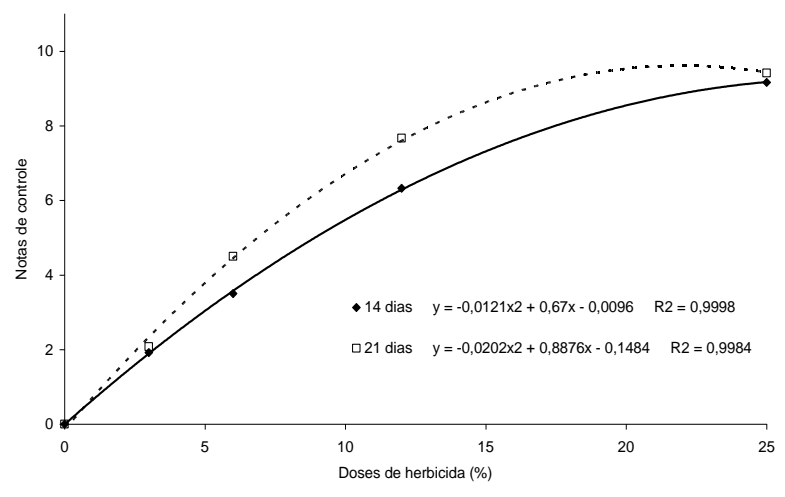

Figura 2. Controle de malva (Sidastrum micranthum) em função da aplicação de doses crecentes de herbicidas hormonais, aos 14 e 21 dias após a aplicação.

Assim, percebe-se que nas avaliações intermediárias, realizadas aos 14 e 21 DAA, observou-se que, independentemente do herbicida usado, o controle atingiu notas próximas á máxima indicada pela escala adotada no trabalho com a subdose de $25 \%$ (Figura 2). Outros trabalhos demonstram que alguns herbicidas, usados isoladamente ou em mistura com outros ingredientes ativos tem efetiva capacidade de controle das mais diversas plantas daninhas em pastagens (CASTRO JUNIOR et al., 2008; LADEIRA NETO et al., 2008; VIEIRA et al., 2010; VENDRAME et al., 2014), mesmo em doses inferiores ás recomendadas para espécies lenhosas de difícil controle.

Aos 28 DAA, as notas de controle de $S$. micranthum chegaram a próximas de 10 (limite máximo) quando foram usadas as doses de 12,5 e $25 \%$ do herbicida 2,4-D+picloram e também $25 \%$ do 2,4-D (Figura 1-B), demonstrando efetiva capacidade de controle dessa planta com doses reduzidas de ambos os herbicidas, mesmo 
em doses inferiores á aquelas recomendadas pelo fabricante. Santos et al. (2011) também verificaram que a metade da dose recomendada de 2,4-D+picloram foi suficiente para o controle efetivo de Solanum paniculatum em 31 dias após o tratamento, sendo que a total queda das folhas dessa espécie foi verificada já aos 12 DAA.

De acordo com Silva et al. (2007), após aplicações de herbicidas do grupo químico dos mimetizadores de auxina, as plantas sensíveis sofrem mudanças metabólicas e bioquímicas, podendo leva-las á morte, dependendo do seu grau de sensibilidade e em função dos diferentes tipos de moléculas desse grupo, como foi o caso do presente trabalho. Ao interferirem na ação da enzima RNApolimerase e, consequentemente, na síntese de ácidos nucleicos e proteínas, induzem á intensa proliferação celular em tecidos, causando queda prematura das folhas e interrupção do fluxo no floema (THILL, 2003). Em consequência disso, verifica-se um crescimento desorganizado que leva as plantas a sofrerem rapidamente efeitos como epinastia das folhas, retorcimento do caule, engrossamento das gemas terminais e morte.

Quanto a altura das plantas, foi observado que esta foi influenciada pela dose (p $>0,05)$, apenas nas avaliações aos 21 e 28 DAA. Justifica-se apenas a significância para esse fator, dada a característica do herbicida quando da aplicação em plantas daninhas. Após a epinastia de regiões meristemáticas, as folhas caem, ocorre a paralização do crescimento, provocando a morte da planta (SILVA et al., 2007; YAMASHITA et al., 2009). Essa paralisação no crescimento, característica do herbicida, foi observada em todas as doses, variando de $12 \%$ para a dose menor até $22 \%$ para a dose maior, apenas nas duas últimas avaliações (Figura 3), resultando na redução significativa da altura das plantas.

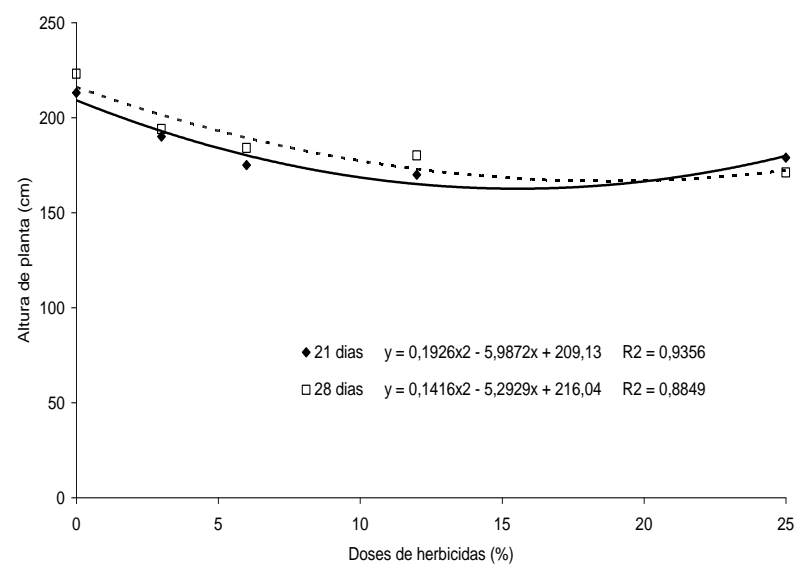

Figura 3. Altura de plantas de malva (Sidastrum micranthum) em função da aplicação de doses crecentes de herbicidas hormonais, aos 21 e 28 dias após a aplicação.

\section{CONCLUSÃO}

O controle da malva, nas condições do experimento, foi verificado a partir das doses de $12,5 \%\left(0,5 \mathrm{~L} \mathrm{ha}^{-1}\right)$ de 2,4-D+picloram e $25 \%$ $\left(1,0 \mathrm{~L} \mathrm{ha}^{-1}\right)$ de 2,4-D.

\section{REFERÊNCIAS}

ALBERGUINI, A. L.; YAMASHITA, O. M. Profundidade de semadura e presença de palha afetam a emergência de plântulas de Vernonia ferruginea. Planta Daninha, v.28, n.spe., p.1005-1013, 2010. 
BOVINI, M. G.; CARVALHO-OKANO, R. M.; VIEIRA, M. F. Malvaceae A. Juss. no Parque Estadual do Rio Doce, Minas Gerais, Brasil. Rodriguésia, v.52, n.81, p.17-47, 2001.

CASTRO JUNIOR, T. G.; FERNANDES, A. C.; ROSSI JUNIOR, P. Herbicidas no manejo de invasoras em pastagem de Brachiaria brizantha cv Marandu, no Mato Grosso, Brasil.

Revista Acadêmica de Ciências Agrárias e Ambientais, v.6, n.1, p.109-118, 2008.

CONSTANTIN, J.; OLIVEIRA JÚNIOR, R. S.; BRANDÃO FILHO, J. U. T.;

CALLEGARI, O.; PAGLIARI, P. H.;

ARANTES, J. G. Z. Efeito de subdoses de 2,4-

$D$ na produtividade de fumo e suscetibilidade da cultura em função de seu estádio de desenvolvimento. Engenharia Agrícola, v.27, n.esp., p.30-34, 2007.

COSTA, C.; MEIRELLES, P. R. L.; SILVA, J J. Evolução das pastagens cultivadas e do efetivo bovino no Brasil. Arquivo Brasileiro de Medicina Veterinária e Zootecnia, v.15, n.1, p.8-17, 2008.

COSTA, N. L.; TOWNSEND, C. R.; MAGALHÃES, J. A.; PAULINO, V. T.; ARAÚJO, R. G. Recuperação e renovação de pastagens degradadas. Revista Eletrônica de Veterinária REDVET, v.7, n.1, p.9-49, 2006.

DUTRA, S.; SOUZA FILHO, A. P. S.; MASCARENHAS, R. E. B. Controle integrado das espécies invasoras assa-peixe e casadinha em pastagens cultivadas de Paragominas, nordeste Paraense. Boletim de Pesquisa e Desenvolvimento, Belém: Embrapa Amazônia Oriental, n. 13, 2002.

DUTRA, S.; SOUZA FILHO, A. P. S.; MASCARENHAS, R. E. B.; GONÇALVES, C. A. Controle integrado de plantas invasoras em pastagens cultivadas no município de Terra Alta, nordeste Paraense. Boletim de Pesquisa e Desenvolvimento. Belém: Embrapa Amazônia Oriental, 2004. 30p.

EMBRAPA Solos. Sistema brasileiro de classificação de solos. Rio de Janeiro: Embrapa Solos, 2013. 412p.
FAGLIARI, J. R.; OLIVEIRA JR, R. S.; CONSTANTIN, J. Efeitos e impacto econômico da aplicação de subdoses de 2,4 D, simulando deriva, sobre o tomateiro (Lycopersicon esculentum). In: CONGRESSO DA CIÊNCIA DAS PLANTAS DANINHAS, 24, 2004, São Pedro. Resumos... São Pedro, 2004. p. 200.

GIORDANO, S. R. Diretrizes para o desenvolvimento da pecuária de corte em Mato Grosso. Cuiabá: Acrimat, 2012. 74p.

HORN, R. Manejo de Adenocalymna impressum em pastagem na região Noroeste de Mato Grosso. 2011. 35f. Monografia (Graduação em Agronomia). Universidade do Estado de Mato Grosso, Alta Floresta-MT.

INOUE, M. H.; SILVA, B. E.; PEREIRA, K. M.; SANTANA, D. C.; CONCIANI, P. A.; SZTOLTZ, C. L. Levantamento fitossociológico em pastagens. Planta Daninha, v.30, n.1, p.55-63, 2012.

LADEIRA NETO, A.; SVICERO, E. F.; BARROS, J. C. B. Manejo de plantas daninhas em pastagens. Viçosa: Aprenda Fácil, p.161-177, 2006.

LADEIRA NETO, A.; TOFOLI, G. R.; CACERES, N. T.; VICTORIA FILHO, R. Eficácia de misturas de aminopiralide + 2,4-D (Jaguar) e aminopiralide + fluroxypyr (Dominum) em espécies de difícil controle através de aplicação foliar dirigida em pastagens. In: CONGRESSO BRASILEIRO DA CIÊNCIA DAS PLANTAS DANINHAS, 26., 2008, Resumos... Ouro Preto: SBCPD, 2008, 1CD.

LORENZI, H. Plantas daninhas do Brasil: terrestres, aquáticas, parasitas e tóxicas. 3. ed. Nova Odessa: Plantarum, 2000. 624 p.

PASSINI, T.; KRANZ, W. M. Eficácia de herbicidas no controle de amarelinho (Tecoma stans) em pastagem. Planta Daninha, v.15, n.2, p.190-198, 1997.

PAULINO, V. T.; SCHUMANN, A. M.; SILVA, S. C.; RASQUINHO, N. M.; 
SANTOS, K. M. Impactos ambientais da exploração pecuária em sistemas intensivos de pastagem. Informe Agropecuário, v.33, n.266, p.17-24, 2012.

POTT, A.; POTT, V. J.; SOUZA, T. W.

Plantas daninhas de pastagem na região de Cerrados. Campo Grande: Embrapa Gado de Corte, 2006. 336p.

RODRIGUES, N. R.; ALMEIDA, F. S. de. Guia de herbicidas. 5. ed. Londrina: Ed. do Autor, 2005. 648 p.

SANTOS, N. V.; SANTANA, A. C. G.; MELO, M. P. Controle de Solanum paniculatum L. em pastagens de Brachiaria spp. No município de Nossa Senhora do Socorro (SE). Cadernos de Graduação - Ciências Biológicas e da Saúde, v.13, n.14, p.25-34, 2011.

SHIMPALE, V. B.; SUTAR, S. P. YADAV, S. R. Sidastrum (Malvaceae): a new genus Record for Ásia. Rheedea, v.19, n.1-2, p.50-52, 2009.

SILVA, A. A.; FERREIRA, F. A.; FERREIRA, L. R. Herbicidas: classificação e mecanismos de ação. In: SILVA, A. A.; SILVA, J. F. (Eds). Tópicos em manejo de plantas daninhas. Viçosa: Editora UFV, 2007. 367p.

THILL, D. Growth regulator herbicides. In: Herbicide action course. West Lafayette: Purdue University, 2003. p.267-291.

VENDRAME, G. H. M.; YAMASHITA, O. M.; CARVALHO, M. A. C.; CAMPOS, O. R.; DALLACORT, R.; KOGA, P. S.; PARENTE, T. L.; CAIONI, S.; PERES, W. M.;OLIVEIRA, R. B. Manejo químico de Vismia guianensis com diferentes misturas de herbicidas auxínicos em área de pastagem de Brachiaria brizantha. Revista de Ciências Agroambientais, Alta Floresta, v.12, n.1, p.35-41, 2014.

VIEIRA; J. A. C.; SOUZA; L. C.; ALMEIDA, D. J.; ALVES, J. N. Efeitos de misturas de aminopiralide + fluroxipir e 2,4-D + picloram em associação com fluroxipir no controle de plantas daninhas em pastagens. In:

CONGRESSO BRASILEIRO DA CIÊNCIA
DAS PLANTAS DANINHAS, 27, Viçosa, 2010. Resumos... Ribeirão Preto, 2010. 1CD.

VITÓRIA FILHO, R. Fatores que influenciam a absorção foliar dos herbicidas. Informe Agropecuário, v. 11, n. 129, p. 31-38, 1985.

WALL, D. A.; SMITH, M. A. H. Tolerance of common buckwheat (Fagopyrum esculentum) to low rates of 2,4-D and MCPA. Canadian Journal of Plant Science, v.80, n.2, p.407-10, 2000.

YAMASHITA, O. M.; BETONI, J. R.; GUIMARÃES, S. C.; ESPINOSA, M. M. Influência do glyphosate e 2,4-D sobre o desenvolvimento inicial de espécies florestais. Scientia Forestalis, v.37, n.84, p.359-366, 2009. 